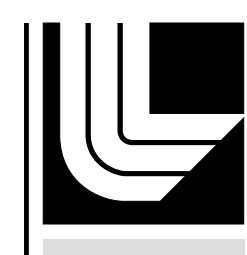

\title{
Diamond Ablators for Inertial Confinement Fusion
}

J. Biener, P. B. Mirkarimi, J. W. Tringe, S. L. Baker, Y. M. Wang, S. O. Kucheyev, N. E. Teslich, K. J. Wu, A. V. Hamza, C. Wild, E. Woerner, P. Koidl, K. Bruehne, H.-J. Fecht

June 24, 2005

Fusion Science and Technologie 
This document was prepared as an account of work sponsored by an agency of the United States Government. Neither the United States Government nor the University of California nor any of their employees, makes any warranty, express or implied, or assumes any legal liability or responsibility for the accuracy, completeness, or usefulness of any information, apparatus, product, or process disclosed, or represents that its use would not infringe privately owned rights. Reference herein to any specific commercial product, process, or service by trade name, trademark, manufacturer, or otherwise, does not necessarily constitute or imply its endorsement, recommendation, or favoring by the United States Government or the University of California. The views and opinions of authors expressed herein do not necessarily state or reflect those of the United States Government or the University of California, and shall not be used for advertising or product endorsement purposes. 
Target Fab Conference proceedings paper to be submitted to "Fusion Science \& Technology", 06/22/05.

\title{
Diamond Ablators for Inertial Confinement Fusion
}

J. Biener, P.B. Mirkarimi, J.W. Tringe, S.L. Baker, Y.M. Wang, S.O. Kucheyev, N.E. Teslich, K.J. Wu, and A.V. Hamza, Lawrence Livermore National Laboratory, Nanoscale Synthesis and Characterization Laboratory, Livermore, USA.

C. Wild, E. Woerner, and P. Koidl

Fraunhofer Insitute for Applied Solid-State Physics, Freiburg, Germany

K. Bruehne and H.-J. Fecht

Materials Division, University of Ulm, Ulm, Germany

\begin{abstract}
Diamond has a unique combination of physical properties for the inertial confinement fusion ablator application, such as appropriate optical properties, high atomic density, high yield strength, and high thermal conductivity. Here, we present a feasible concept to fabricate diamond ablator shells. The fabrication of diamond capsules is a multi-step process, which involves diamond chemical vapor deposition on silicon mandrels followed by polishing, microfabrication of holes, and removing of the silicon mandrel by an etch process. We also discuss the pros and cons of coarse-grained optical quality and nanocrystalline chemical vapor deposition diamond films for the ablator application.
\end{abstract}




\section{Introduction}

Inertial confinement fusion (ICF) target fabrication is one of the technical challenges that needs to be met for the successful operation of the National Ignition Facility (NIF). ${ }^{1}$ The baseline design for indirect-drive ignition targets for NIF consists of a two-millimeter-diameter spherical shell ("ablator") with a wall thickness $75-130 \mu \mathrm{m}$ made of a low-Z material, filled with a frozen layer of deuterium-tritium (DT) fuel and a central DT gas core. ${ }^{2-9}$ Although copper-doped beryllium and plasma polymers are currently the primary candidates for the ICF ablator application, diamond seems to be a very promising material due to a unique combination of physical properties: 1) The opacity / albedo properties of diamond for $250-300 \mathrm{eV}$ photons, together with its high atomic density, provide for efficient energy absorption and a high ablation rate whereby reducing Rayleigh-Taylor instabilities at the ablation front; ${ }^{10} 2$ ) The extremely high yield strength of diamond allows room temperature handling of filled targets there the DT fuel develops a pressure in the order of $1000 \mathrm{~atm}$; 3) The broad-band optical transparency of diamond $^{11}$ (from ultraviolet to far infrared, $0.22-20 \mu \mathrm{m}$ ) allows the use of optical techniques to smooth the DT ice layer; 4) Finally, the high thermal conductivity (up to 23 $\mathrm{W} \mathrm{cm}{ }^{-1} \mathrm{~K}^{-1}$ at $300 \mathrm{~K}^{12}$ ) of diamond simplifies the cryogenic system requirements.

The ICF ablator application requires the ability to produce uniform high-quality diamond coatings on small spherical substrates with a nanometer surface finish. Here, we present a feasible concept to fabricate diamond ablator shells as well as preliminary experimental results. Specifically, we successfully deposited $\sim 100$-micron-thick optical quality diamond films on spherical silicon substrates. These coarse-grained films were 
grown by a technique called microwave plasma-assisted chemical vapor deposition (PACVD) using a reactor which is optimized for long-term plasma stability. In addition, nanocrystalline CVD diamond films were characterized as an alternative to coarsegrained material. We also present preliminary results on drilling micron-sized holes through $\sim 100-\mu \mathrm{m}$-thick diamond films by laser or focused ion beam (FIB) processing.

\section{Experimental Procedure}

The deposition of optical-quality diamond films on spherical silicon substrates (Fraunhofer Institute, Germany) was performed in a $6 \mathrm{~kW}$ microwave reactor equipped with a custom made substrate holder specifically designed to guarantee uniform coating of spherical substrates. The substrate temperature was between $700-900{ }^{\circ} \mathrm{C}$, and a mixture of one percent methane in hydrogen was used as process gas. Under these conditions we obtained a deposition rate of $\sim 2 \mu \mathrm{m} / \mathrm{h}$.

Nanocrystalline diamond films were grown on silicon (100) substrates using a hot-filament CVD reactor (CemeCon CC800/Dia) ${ }^{13}$ In order to achieve a high nucleation density, the substrates were treated by bias enhanced nucleation before film growth. A feed gas mixture of $\sim 3 \%$ methane in hydrogen was used. Additionally, oxygen was inserted periodically to the gas mixture with an average concentration of $\sim 1 \%$ to facilitate the development of a nanocrystalline grain structure. 
Both coarse-grained and nanocrystalline diamond films were characterized by a variety of techniques including cross-sectional transmission electron microscopy (XTEM), Rutherford backscattering (RBS), soft x-ray absorption near-edge structure (XANES) spectroscopy, as well as Raman and infrared (IR) spectroscopy. The mechanical properties of CVD diamond films were tested by depth-sensing nanoindentation using a Triboindenter (Hysitron) equipped with a diamond Berkovich tip. The spatial frequency roughness of the diamond films was characterized by white light interferometry (Zygo) and atomic force microscopy (Digital Instruments). The characterization methods are described in more detail in reference 13.

Micron-sized holes were drilled through freestanding diamond films using a FIB system (FEI) in combination with a $\mathrm{XeF}_{2}$-assisted etch chemistry. Alternatively, a diode

pumped, q-switched Nd:YAG laser with a $4 \mathrm{kHz}$ pulse repetition rate (average power 10 W) was used. The silicon mandrels were removed by etching in a mixture of hydrofluoric acid and nitric acid.

\section{Results and Discussion}

Diamond ablator shells can be fabricated using a multi-step process schematically illustrated in Figure 1. The process involves the following steps: 1) chemical vapor deposition of diamond on silicon mandrels, 2) polishing of the initially rough diamond films to the required surface finish, 3) microfabrication of blind holes through the 
diamond film or, alternatively, microfabrication of through-holes (through the $\mathrm{Si}$ mandrel), 4) removing of the silicon mandrel by wet or dry etch processes, and 5) attaching a fill tube or plugging the fill hole. In the following, the feasibility of each step will be discussed and, where available, preliminary experimental results will be presented.

Deposition of optical-quality diamond films on spherical silicon substrates with a diameter of $2 \mathrm{~mm}$ was performed in a $6 \mathrm{~kW}$ microwave reactor (Fraunhofer Institute, Germany) optimized for long-term plasma stability. ${ }^{14}$ The system is equipped with a custom-designed substrate holder to guarantee the homogeneous coating of spherical substrates. The substrate platform consists of a rotating beveled inner disk and a stationary outer ring whereby randomly rotating the Si mandrels inserted into the groove between the inner disk and the outer ring (Fig. 2a). After every turn, the spheres are deflected from the groove to further randomize their movement. The diamond films were grown at $700-900{ }^{\circ} \mathrm{C}$ using a feed gas mixture of $1 \%$ methane in hydrogen resulting in a deposition rate of $\sim 2 \mu \mathrm{m} / \mathrm{h}$. Figure $2 \mathrm{~b}$ shows a set of spheres simultaneous coated with an $\sim 70-\mu \mathrm{m}$-thick diamond film.

For quality control, we also studied diamond films grown under identical conditions on flat silicon substrates (data not shown). In short, we checked the density (weight measurement, $3.57 \mathrm{~g} / \mathrm{cc}$ ), the phase purity (Raman spectroscopy and x-ray diffraction), as well as the infrared transparency of this material, and all experimental results are consistent with the deposition of fully-dense, phase-pure, coarse-grained polycrystalline diamond of optical quality. 
The as-grown diamond films exhibit a very rough surface morphology due to the coarse grain structure of CVD diamond (Fig. 3c). Typically, the root mean square (RMS) roughness of an as-deposited diamond film is in the order of $2 \%$ of the film thickness, which translates into a RMS roughness of $\sim 2 \mu \mathrm{m}$ for a $\sim 100-\mu \mathrm{m}$-thick CVD diamond film. On the other hand, the ICF ablator application requires a RMS roughness in the order of $10 \mathrm{~nm}$ (NIF standard). ${ }^{5,9}$ Fortunately, polishing techniques exist which are able to meet this requirement. ${ }^{15}$ We measured the surface roughness of a freestanding diamond film with an optical quality surface finish, and observed surface roughness values of $<20 \mathrm{~nm}$ RMS on a mm length scale (scanning white-light interferometry) and $<1 \mathrm{~nm}$ on a $\mu \mathrm{m}$ length scale (atomic force microscopy), respectively. In an attempt to transfer the polishing techniques developed for diamond flats to spherical samples, we adopt polishing techniques used in the ball bearing industry to fabricate brittle ceramic balls. ${ }^{16}$ We started with a simplified version of such a polishing machine consisting of a rotating grinding disk charged with diamond powder and a custom-designed sample holder. The diamond coated spheres are inserted into concentric grooves (race tracks) machined into the sample holder, and pressed against the grinding disk. The results of these preliminary experiments are very promising (Figure $3 b$ ). The surface roughness is significantly reduced from $\sim 2 \mu \mathrm{m}$ to $\sim 200 \mathrm{~nm}$. However, a detailed analysis reveals that the polishing is not perfectly uniform, and further improvements of the polishing setup are necessary.

In order to remove the Si mandrel, micron-sized holes have to be drilled through the diamond film. The same holes can later be used for filling the target with DT. The 
specifications for NIF baseline capsules requires fill holes with a diameter of $<5 \mu \mathrm{m},{ }^{4,9}$ which translates into an aspect ratio of $\sim 20$ for an $\sim 100-\mu$ m-thick ablator. We evaluated both FIB and laser based micromachining: Using a $\mathrm{XeF}_{2}$ assisted FIB technique, ${ }^{17,18}$ we were able to drill a round hole, tapering from $\sim 12 \mu \mathrm{m}$ (entrance) to $\sim 5 \mu \mathrm{m}$ (exit), through a $90-\mu \mathrm{m}$-thick freestanding diamond film at a rate of $2 \mu \mathrm{m} / \mathrm{min}$ (Fig. 4a,b). Laser drilling through freestanding diamond films resulted in holes tapering from $\sim 25 \mu \mathrm{m}$ (entrance) to $\sim 5 \mu \mathrm{m}$ (exit) thus indicating a self focusing effect of the laser while drilling through the material. We also laser-machined $\sim 15-\mu \mathrm{m}$-diameter holes through an $\sim 10-\mu \mathrm{m}$-thick diamond film deposited on a silicon mandrel (Fig. 4c) Besides of being a very fast process, laser machining has the further advantage of being able to drill through-holes (through the diamond film and the mandrel) with a diameter of $\sim 30 \mu \mathrm{m}$ (data not shown). Although these early attempts to fabricate through-holes resulted in much larger diameters than those required by the NIF baseline specification, this approach might be advantageous for removing the mandrel material via a microfluidic setup (see below).

Using the holes prepared as described above, the Si mandrel can be removed by wet or dry etch techniques. In a proof-of principle experiment, a hollow diamond capsule was fabricated by machining a $200-\mu \mathrm{m}$-diameter hole through the diamond film and subsequent etching in a mixture of hydrofluoric acid and nitric acid for several hours (Fig. 5). The main disadvantage of this very simple approach lies in the underlying concentration-gradient driven mass transport, resulting in very low etch rates for the required 5- $\mu \mathrm{m}$-diameter holes. On the other hand, using a through-hole in combination with a microfluidic approach results in a pressure-gradient driven mass transport, thus 
potentially enabling high etch rates even through 5 - $\mu \mathrm{m}$-diameter holes. In this scenario, one end of the through-hole would be attached to a vacuum line while the other end would be submerged in the etch solutions. Assuming laminar flow conditions, Poiseuille's equation predicts sufficient mass flow even through 5- $\mu \mathrm{m}$-diameter capillaries. Alternatively, a $\mathrm{XeF}_{2}$-based dry etch technique is available. This isotropic $\mathrm{Si}$ etch process was developed for the MEMS processing,${ }^{19}$ and results in etch rates as high as $10 \mu \mathrm{m} / \mathrm{min}$ at RT. In addition, the best performance of this process is observed when performed in a pulsed mode $\left(\mathrm{XeF}_{2}\right.$ exposure, pump, $\mathrm{XeF}_{2}$ exposure...) thus facilitating mass transport through the required small holes.

After removing the mandrel, the same hole can be used to fill the now empty diamond capsule with DT. In terms of plugging the hole, a default option is to plug the hole with DT ice as proposed for beryllium. ${ }^{4}$ Alternatively, three-dimensional diamondlike carbon (DLC) structures can be fabricated by FIB-assisted chemical vapor deposition (FIB-CVD) using penanthrene $\left(\mathrm{C}_{14} \mathrm{H}_{10}\right)$ as a precursor. ${ }^{20,21}$ This technique can be used to either plug the fill hole with DLC or to grow a fill tube directly above the fill hole. The latter approach has the advantage of a glueless joint between the fill tube and the capsule. Results of proof-of-principle experiments for both plugging and fill tube microfabrication are shown in Figure 6.

Due to the anisotropic speed of sound in diamond, coarse-grained diamond potentially distorts the spherical symmetry of the shock waves, thus jeopardizing the ablator performance. Although this is a general problem of all crystalline ablator 
materials (including beryllium), the effect might be especially important for diamond as the diamond phase diagram predicts that diamond remains in the solid state at the shock front (300-500 GPa, $5000 \mathrm{~K}){ }^{22-24}$ However, shock propagation experiments need to be performed to confirm the existence of this effect. If these experiments indeed reveal a signature of the grain structure in the shock wave velocity distribution, nanocrystalline CVD diamond can be used as an alternative ablator material. Although the growth of nanocrystalline diamond films is usually limited to very thin films due to high internal stresses, we were able to develop a process to grow low stress, ultra-thick NCD films. ${ }^{13}$ The material still exhibits a columnar grain structure, but the grain dimensions are on the nanometer length scale. Compared to optical quality CVD diamond, NCD diamond is still an ultra-strong material, with roughly $15 \%$ lower values for both Young's modulus (80 GPa) and the hardness $(710 \mathrm{GPa})$ as determined by nanoindentation. As an additional benefit, NCD films exhibit a smoother surface morphology than their coarsegrained counterparts (RMS surface roughness of an as-deposited $\sim 80-\mu \mathrm{m}$-thick NCD film is only $\sim 200 \mathrm{~nm}$ ). Currently, the main disadvantages of using NCD as an ablator material is the roughly ten times lower deposition rate $(\sim 165 \mathrm{~nm} / \mathrm{h})$ compared to that of coarsegrained material.

\section{Conclusions}

Diamond has a unique combination of physical properties for the ICF ablator application. We developed a concept for the fabrication of diamond ablator shells involving the following steps: 1) CVD of optical quality polycrystalline diamond films on spherical silicon substrates, 2) polishing of the diamond films to a nanometer level surface finish, 
3) fabrication of micrometer-sized holes, 4) etching of the silicon mandrel, and 5) FIBassisted microfabrication (plugging, fill tube), Alternatively, the nanocrystalline diamond films are available. Initial results are very promising and justify further evaluation of diamond ablator shells. Future steps include the deposition of NCD films on spherical substrates, down selection of coarse-grained or nanocrystalline diamond based on shock physics, and generating a point design for diamond ICF ablator capsules.

\section{Acknowledgements}

This work was performed under the auspices of the U.S. Department of Energy by University of California, Lawrence Livermore National Laboratory under Contract W7405-Eng-48. The authors would like to thank Mark Hermann, Bob Cook, and Peter Amendt for helpful discussions. Work at the University of Ulm has been financially supported by the German Federal Ministry of Education and Research (Project WMtech) and by the Landesstiftung Baden-Wuerttemberg (Network of Competence Functional Nanostructures, Project B6). 


\section{References}

1. G. H. Miller, E. I. Moses, and C. R. Wuest, "The National Ignition Facility," Opt. Eng. 43, 2841-2853 (2004).

2. S. W. Haan, S. M. Pollaine, J. D. Lindl, L. J. Suter, R. L. Berger, L. V. Powers, W. E. Alley, P. A. Amendt, J. A. Futterman, W. K. Levedahl, M. D. Rosen, D. P. Rowley, R. A. Sacks, A. I. Shestakov, G. L. Strobel, M. Tabak, S. V. Weber, G. B. Zimmerman, W. J. Krauser, D. C. Wilson, S. V. Coggeshall, D. B. Harris, N. M. Hoffman, and B. H. Wilde, "Design and Modeling of Ignition Targets for the National Ignition Facility," Physics of Plasmas 2(6), 2480-2487 (1995).

3. T. R. Dittrich, S. W. Haan, M. M. Marinak, D. E. Hinkel, S. M. Pollaine, R. McEachern, R. C. Cook, C. C. Roberts, D. C. Wilson, P. A. Bradley, and W. S. Varnum, "Capsule design for the National Ignition Facility," Laser and Particle Beams 17(2), 217-224 (1999).

4. S. W. Haan, T. Dittrich, G. Strobel, S. Hatchett, D. Hinkel, M. Marinak, D. Munro, O. Jones, S. Pollaine, and L. Suter, "Update on ignition target fabrication specifications," Fusion Science and Technology 41(3), 164-173 (2002).

5. S. W. Haan, P. A. Amendt, T. R. Dittrich, B. A. Hammel, S. P. Hatchett, M. C. Herrmann, O. A. Hurricane, O. S. Jones, J. D. Lindl, M. M. Marinak, D. Munro, S. M. Pollaine, J. D. Salmonson, G. L. Strobel, and L. J. Suter, "Design and simulations of indirect drive ignition targets for NIF," Nuclear Fusion 44(12), S171-S176 (2004).

6. S. W. Haan, P. A. Amendt, T. R. Dittrich, S. P. Hatchett, M. C. Herrmann, O. A. Hurricane, M. M. Marinak, D. Munro, S. M. Pollaine, G. A. Strobel, and L. J. Suter, "Update on NIF indirect drive ignition target fabrication specifications," Fusion Science and Technology 45(2), 69-73 (2004).

7. G. L. Strobel, S. W. Haan, and T. R. Dittrich, "Low mode surface perturbation tolerance of ignition capsule implosions for the National Ignition Facility," Physics of Plasmas 11(4), 1617-1621 (2004).

8. G. L. Strobel, S. W. Haan, D. H. Munro, and T. R. Dittrich, "Design of a 250 eV cryogenic ignition capsule for the National Ignition Facility," Physics of Plasmas 11(9), 4261-4266 (2004).

9. R. B. Stephens, S. W. Haan, and D. C. Wilson, "Characterization specifications for baseline indirect drive NIF targets," Fusion Science and Technology 41(3), 226-233 (2002).

10. M.C. Herrmann, private communication

11. C. Wild and P. Koidl, "Optical Properties of Diamond and Applications as Radiation Windows," in Properties, Growth and Applications of Diamond, M. H. Nazare and A. J. Neves, eds. (INSPEC, London, 2001), pp. 351-355.

12. D. R. Linde, ed., Handbook of Chemistry and Physics, 84th ed. (CRC Press, Boca Raton, 2003). 
13. S. O. Kucheyev, J. Biener, J. W. Tringe, Y. M. Wang, P. B. Mirkarimi, T. van Burren, S. L. Baker, A. V. Hamza, K. Bruehne, and H.-J. Fecht, "Ultra-thick, low stress nanostructured diamond films," Applied Physics Letters 86, 221914 (2005).

14. M. Funer, C. Wild, and P. Koidl, "Novel microwave plasma reactor for diamond synthesis," Applied Physics Letters 72(10), 1149-1151 (1998).

15. E. Woerner, C. Wild, W. Mueller-Sebert, and P. Koidl, "CVD-diamond optical lenses," Diamond and Related Materials 10(3-7), 557-560 (2001).

16. N. Axen, "Methode and Means for Grinding Balls of Ceramics or other Hard Materials to Spherical Shape," WO9919115A1 (1999).

17. J. Taniguchi, N. Ohno, S. Takeda, I. Miyamoto, and M. Komuro, "Focused-ionbeam-assisted etching of diamond in XeF2," Journal of Vacuum Science \& Technology B 16(4), 2506-2510 (1998).

18. A. Stanishevsky, "Patterning of diamond and amorphous carbon films using focused ion beams," Thin Solid Films 398, 560-565 (2001).

19. P. Muthukumaran, I. Stiharu, and R. B. Bhat, "Gas-phase xenon difluoride etching of microsystems fabricated through the Mitel 1.5-mu m CMOS process," Canadian Journal of Electrical and Computer Engineering-Revue Canadienne De Genie Electrique Et Informatique 25(1), 35-41 (2000).

20. T. Hoshino, M. Kawamori, T. Suzuki, S. Matsui, and K. Mabuchi, "Threedimensional and multimaterial microfabrication using focused-ion-beam chemical-vapor deposition and its application to processing nerve electrodes," Journal of Vacuum Science \& Technology B 22(6), 3158-3162 (2004).

21. T. Morita, R. Kometani, K. Watanabe, K. Kanda, Y. Haruyama, T. Hoshino, K. Kondo, T. Kaito, T. Ichihashi, J. Fujita, M. Ishida, Y. Ochiai, T. Tajima, and S. Matsui, "Free-space-wiring fabrication in nano-space by focused-ion-beam chemical vapor deposition," Journal of Vacuum Science \& Technology B 21(6), 2737-2741 (2003).

22. D. K. Bradley, J. H. Eggert, D. G. Hicks, P. M. Celliers, S. J. Moon, R. C. Cauble, and G. W. Collins, "Shock compressing diamond to a conducting fluid," Physical Review Letters 93(19)(2004).

23. W. J. Nellis, A. C. Mitchell, and A. K. McMahan, "Carbon at pressures in the range 0.1-1 TPa (10 Mbar)," Journal of Applied Physics 90(2), 696-698 (2001).

24. L. E. Fried and W. M. Howard, "Explicit Gibbs free energy equation of state applied to the carbon phase diagram," Physical Review B 61(13), 8734-8743 (2000). 


\section{Figure Captions}

Figure 1. Proposed process flow for the fabrication of diamond ablator shells

Figure 2. Deposition of optical-quality diamond films on spherical silicon substrates: (a) Custom-designed sample holder consisting of a rotating beveled inner disk and a stationary outer ring, with the Si mandrels inserted into the groove between the inner disk and the outer ring. (b) Set of Si spheres simultaneous coated with an $\sim 70$ - $\mu$ m-thick diamond film.

Figure 3. Results of preliminary polishing experiments: As-grown diamond coated spheres (c) exhibit a very rough surface morphology with a RMS roughness of $\sim 2 \mu \mathrm{m}$ due to the coarse grain structure of CVD diamond. The surface roughness of polished spheres (b) is significantly reduced (RMS roughness $\sim 200 \mathrm{~nm})$.

Figure 4. Microfabrication of holes in diamond: Top view (a) and cross section (b) scanning electron micrographs of a round tapered hole drilled through a 90$\mu \mathrm{m}$-thick freestanding diamond film with a diameter $12 / 5 \mu \mathrm{m}$ (entrance/exit) using a $\mathrm{XeF}_{2}$ assisted FIB technique. (c) Laser-machined 15- $\mu$ m-diameter hole through an $\sim 10$ - $\mu \mathrm{m}$-thick diamond film deposited on a spherical Si substrate.

Figure 5. Polished CVD diamond capsule after removal of the silicon mandrel by a wet etch approach. 
Figure 6. Proof-of-principle experiments demonstrating FIB-assisted microfabrication techniques: a) Plugging of a hole drilled through a free-standing $\mathrm{Cu}$ foil by FIB-assisted chemical vapor deposition (FIB-CVD). b) Micron-sized DLC filltube fabricated by FIB-CVD with an inner diameter of $\sim 6 \mu \mathrm{m}$ and a height of $\sim 25 \mu \mathrm{m}$.

Figure 7. Cross-sectional bright-field transmission electron micrograph of an $\sim 80-\mu \mathrm{m}$ thick nanocrystalline diamond film revealing the sub-micron grain structure. 


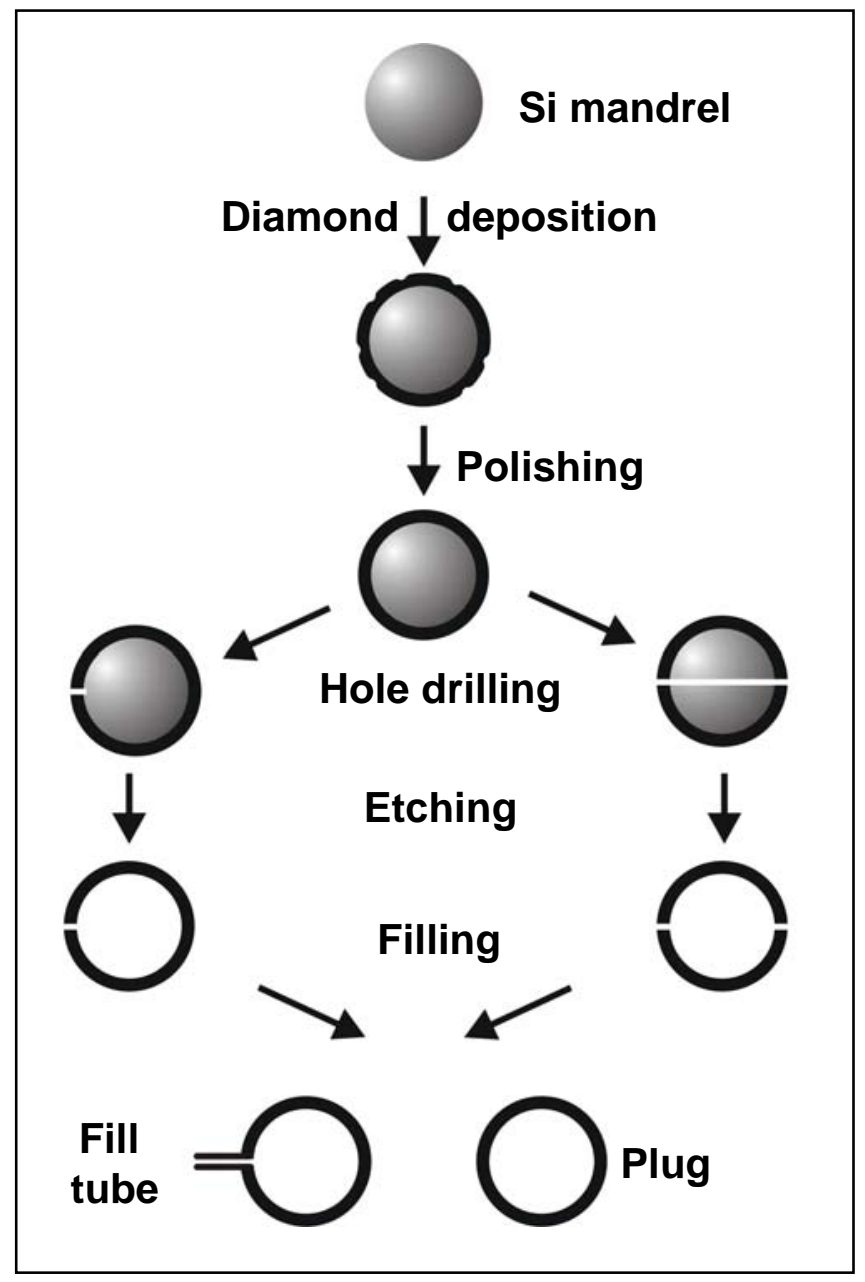

Figure 1 


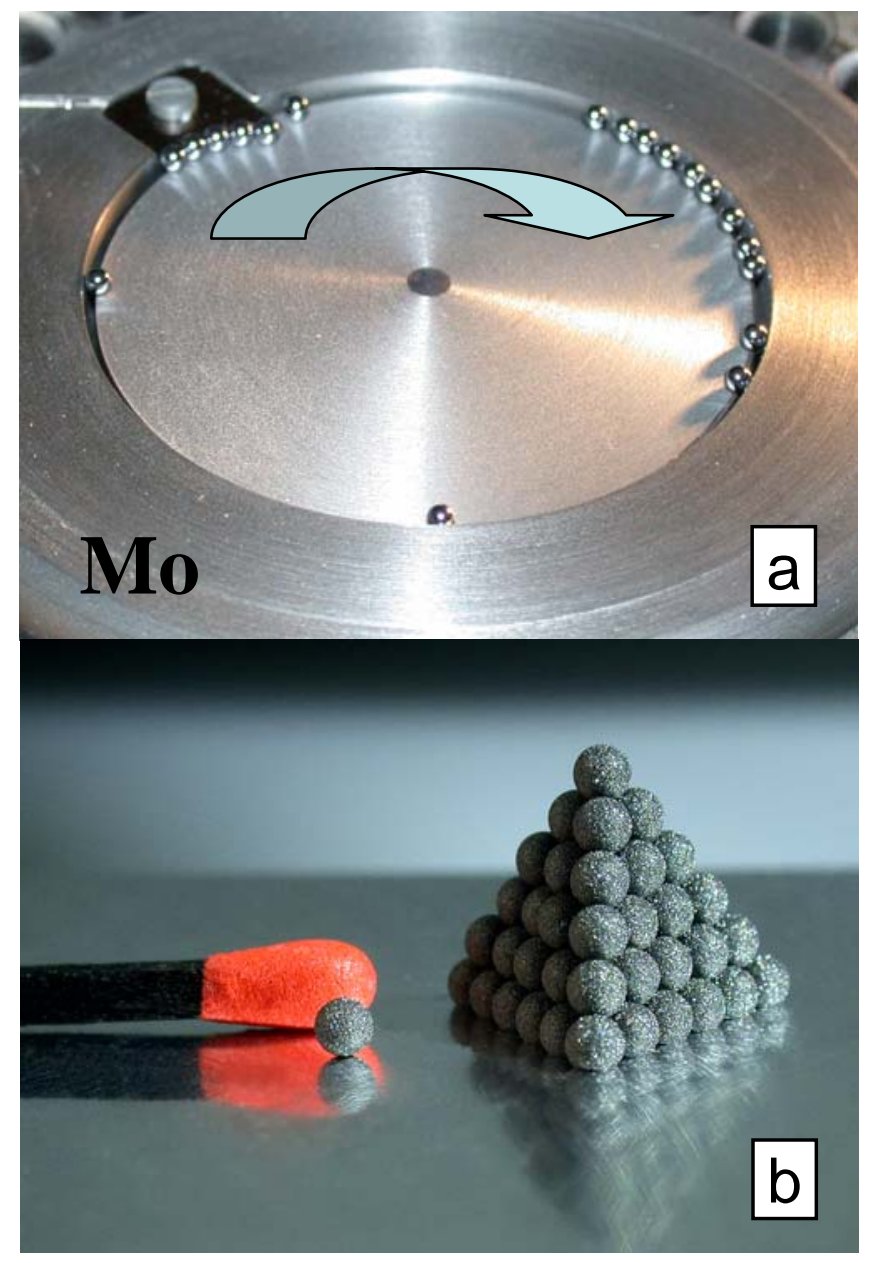

Figure 2 


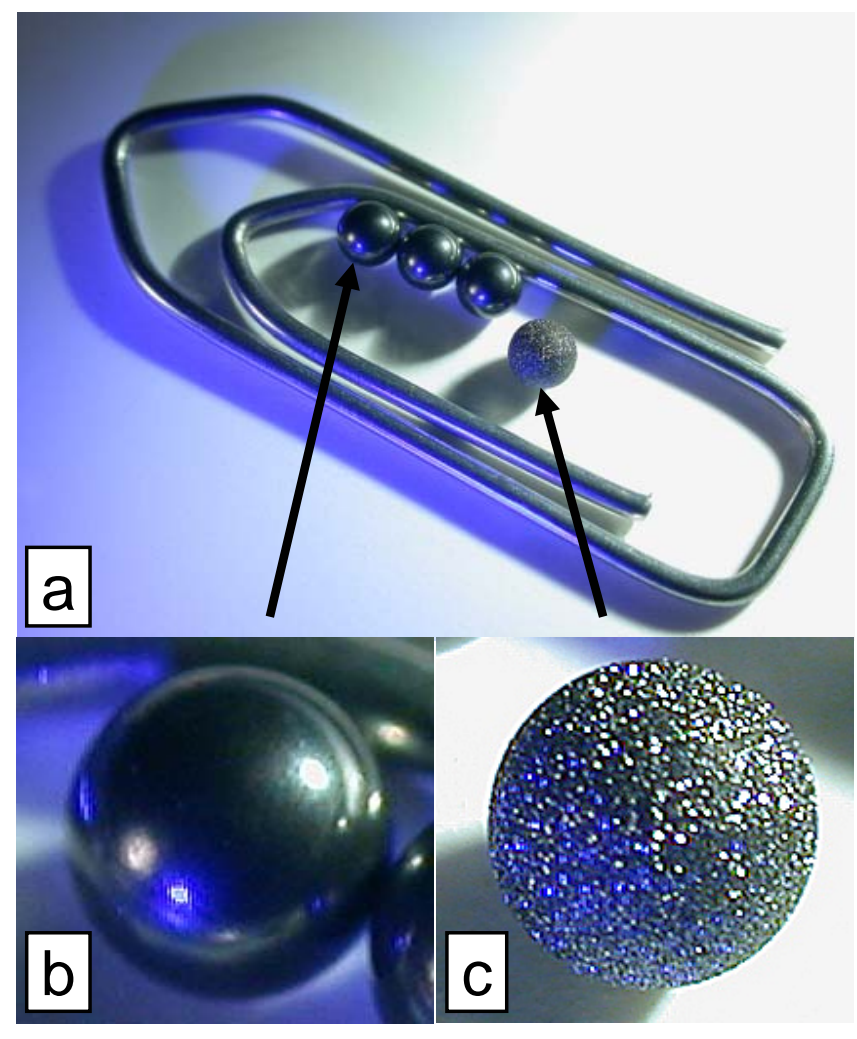

Figure 3 


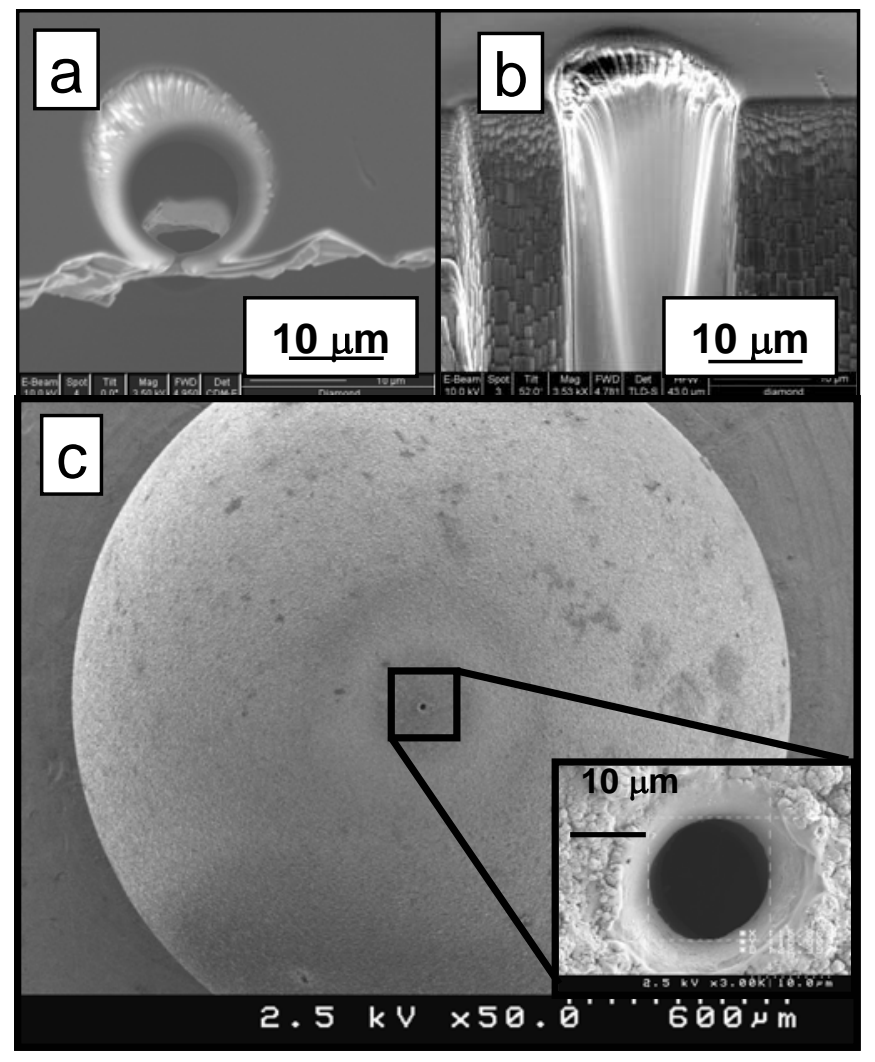

Figure 4 


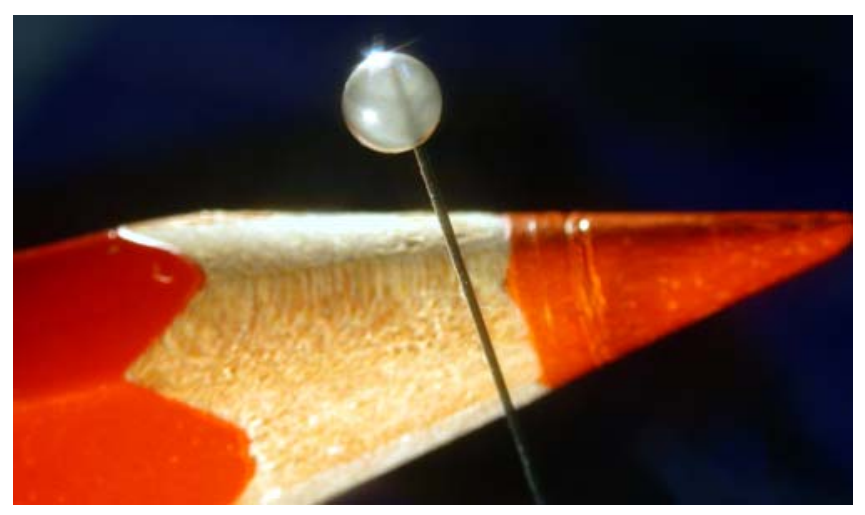

Figure 5 


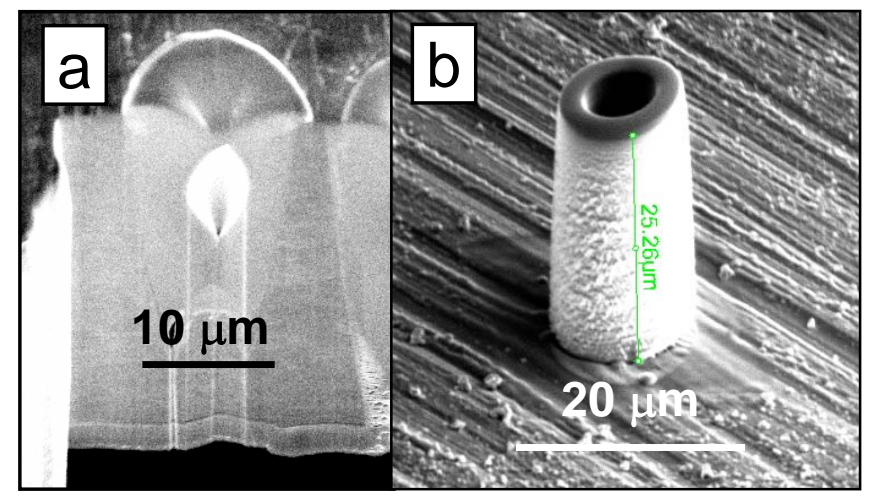

Figure 6 


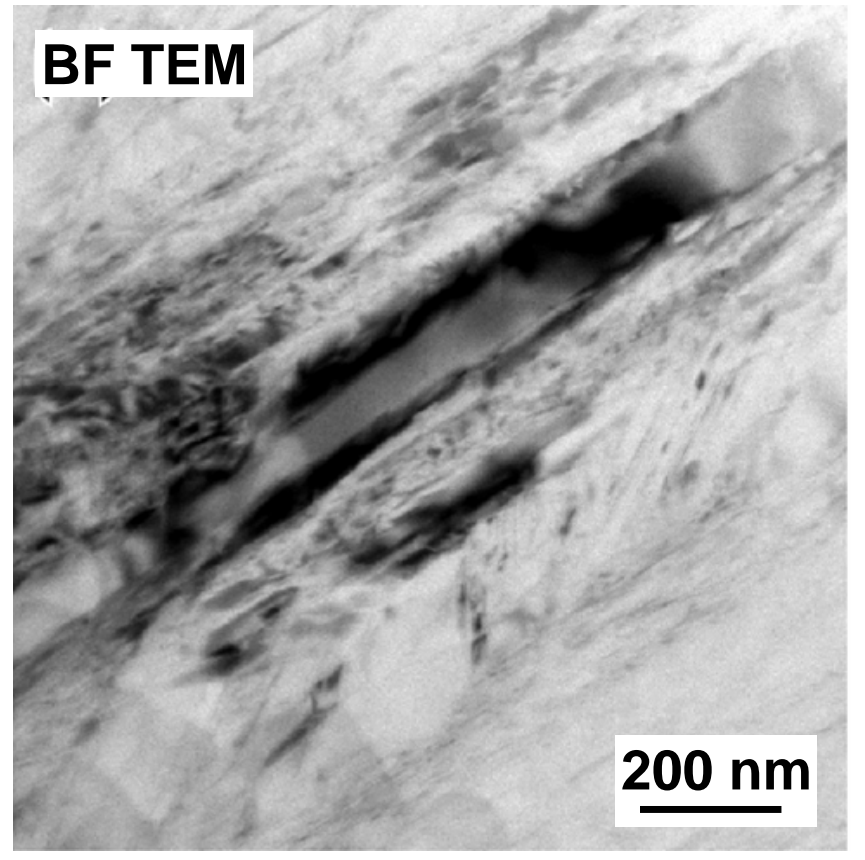

Figure 7 